\section{Replacement of a Cyclometalated Terdentate Diamino Ligand by a Phosphorus Analogue. Isolation and Crystallographic Characterization of an Intermediate in Aryl $\mathrm{C}-\mathrm{H}$ Bond Activation in Models of Dendrimer-Bound Organometallic Catalysts}

Paulo Dani,$^{\dagger}$ Thomas Karlen, ${ }^{\dagger}$ Robert A. Gossage, ${ }^{\dagger}$ Wilberth J. J. Smeets, ${ }^{\ddagger}$ Anthony L. Spek ${ }^{\ddagger}$ and Gerard van Koten*,

\section{Debye Institute, Department of Metal-Mediated Synthesis and Bijvoet Centre for Biomolecular Research Laboratory of Crystal Chemistry, Utrecht University Padualaan 8, 3584 CH Utrecht, The Netherlands}

Received March 31, 1997

The chemistry of the potentially monoanionic, terdentate diaminoaryl ligand $\left[\mathrm{NCN}^{\prime}\right]^{-}(\mathbf{1})$ and its phosphorus analogue bisphosphinoaryl $\left[\mathrm{PCP}^{\prime}\right]^{-}(\mathbf{2}$, Figure 1$)$ have been extensively studied in this laboratory and others ${ }^{1-3}$ due to their strong propensity to form stable transition metal (TM) and main-group organometallic complexes, often in unusual geometries and/or oxidation states. ${ }^{4}$ A number of these TM compounds are effective catalysts for the synthesis of commodity and fine chemicals, and they have also been used as molecular probes in a number of fundamental chemical processes, notably $\mathrm{C}-\mathrm{H}$ bond activation. $^{2-6}$ We have been interested in using functionalized aryl ligands as templates for the incorporation of catalytically active TM fragments onto polymeric or well-

\section{$\dagger$ Debye Institute.}

\$ Bijvoet Centre for Biomolecular Research

(1) (a) Mayer, H. A.; Kaska, W. C. Chem. Rev. 1994, 94, 1239-1272. (b) Bianchini, C.; Meli, A.; Peruzzini, M.; Vizza, F.; Zanobini, F. Coord Chem. Rev. 1992, 120, 193-208. (c) Cotton, F. A.; Hong, B. Prog. Inorg. Chem. 1992, 40, 179-290.

(2) (a) van der Kuil, L. A.; Luitges, H.; Grove, D. M.; Zwikker, J. W.; van der Linden, J. G. M.; Roelofsen, A. M.; Jenneskens, L. W.; Drenth, W.; van Koten, G. Organometallics 1994, 3, 468-477. (b) Steenwinkel, P.; James, S. L.; Grove, D. M.; Veldman, N.; Spek, A. L.; van Koten, G. Chem. Eur. J. 1996, 2, 1440-1445. (c) Davies, P. J.; Veldman, N.; Grove, D. M.; Spek, A. L.; Lutz, B. T. G.; van Koten, G. Angew. Chem., Int. Ed. Engl. 1996, 35, 1959-1961.

(3) (a) Karlen, T.; Dani, P.; Grove, D. M.; Steenwinkel, P.; van Koten, G. Organometallics 1996, 15, 5687-5694. (b) Jia, G.; Lee, H. M.; Xia, H. P.; Williams, I. D. Organometallics 1996, 15, 5453-5455. (c) Sutter, J.-P.; James, S. L.; Steenwinkel, P.; Karlen, T.; Grove, D. M.; Veldman, N.; Smeets, W. J. J.; Spek, A. L.; van Koten, G. Organometallics 1996, 15, 941-948. (d) Liou, S.-Y.; Gozin, M.; Milstein, D. J. Chem. Soc., Chem. Commun. 1995, 1965-1966, J. Am. Chem. Soc. 1995, 117, 9774-9775. (e) Gozin, M.; Weismann, A.; Ben-David, Y.; Milstein, D. Nature 1993, 364, 699-701. (f) Gozin, M.; Aizenberg, M.; Liou, S.-Y.; Weismann, A.; Ben-David, Y.; Milstein, D. Nature 1994, 370, 42-44. (g) Kaska, W. C. Nemeh, S.; Shirazi, A.; Potuznik, S. Organometallics 1988, 7, 13-15. (h) Creaser, C. S.; Kaska, W. C. Inorg. Chim. Acta 1978, 30, L325-L326. (i) Gorla, F.; Togni, A.; Venanzi, L. M.; Albinati, A.; Lianza, F. Organometallics 1994, 13, 1607-1616. (j) Rimml, H.; Venanzi, L. M. Phosphorus Sulfur 1987, 30, 297-300, and references therein. (k) Vigalok, A.; BenDavid, Y.; Milstein, D. Organometallics 1996, 15, 1839-1844. (1) Fryzuk, M. D.; Montgomery, C. D.; Rettig, S. J. Organometallics 1991, 10, 467473. (m) Moulton, C. J.; Shaw, B. L. J. Chem. Soc., Dalton Trans. 1976, 1020-1024. (n) Perera, S. D.; Shaw, B. L. J. Chem. Soc., Dalton Trans. 1995, 3861-3866. (o) Cross, R. J.; Kennedy, A. R.; Manojlovic-Muir, L.; Muir, K. W. J. Organomet. Chem. 1995, 493, 243-249. (p) Nemeh, S.; Jensen, C.; Binamira-Soriaga, E.; Kaska, W. C. Organometallics 1983, 2, 1442-1447. (q) Gupta, M.; Hagen, C.; Kaska, W. C.; Cramer, R. E.; Jensen, C. M. J. Am. Chem. Soc. 1997, 119, 840-841. (r) Gupta, M. Hagen, C.; Kaska, W. C.; Flesher, R.; Jensen, C. M. Chem. Commun. 1996, 2083-2084.

(4) (a) van Koten, G. Pure Appl. Chem. 1989, 61, 1681-1694. (b) Rietveld, M. H. P.; Grove, D. M.; van Koten, G. New J. Chem. 1997, 21 $751-771$.

(5) (a) Grove, D. M.; Verschuuren, A. H. M.; van Koten, G. J. Mol. Catal. 1988, 45, 169-174. (b) Grove, D. M.; Verschuuren, A. H. M.; van Koten, G.; van Beek, J. A. M. J. Organomet. Chem. 1989, 372, C1-C6. (6) (a) Canty, A. J.; van Koten, G. Acc. Chem. Res. 1995, 28, 406-413. (b) Ryabov, A. D. Chem. Rev. 1990, 90, 403-424. (c) Green, M. L. H.; O'Hare, D. Pure Appl. Chem. 1985, 57, 1897-1910.
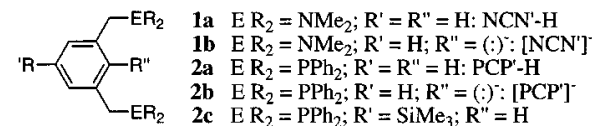

Figure 1.

defined carbosilane dendritic supports ("dendrimer catalysts"). ${ }^{7}$ We report herein some aspects of the chemistry of $d^{6} \mathrm{Ru}$ (II) $\mathrm{PCP}^{\prime}$ complexes which are employed as models for TM compounds which are tethered to carbosilane dendrimers. ${ }^{7 \mathrm{c}}$ This work has in turn led to the isolation and characterization (NMR, IR, X-ray Crystallography) of a rare intermediate in aryl $\mathrm{C}-\mathrm{H}$ bond activation of a $\mathrm{PCP}^{\prime}-\mathrm{H}$ ligand. It is also shown that aryl$\mathrm{Si}$ bond cleavage reactions can predominate the chemistry of carbosilane dendrimers incorporating ligand fragments such as $\left[\mathrm{PCP}^{\prime}\right]^{-}(\mathbf{2})$.

Treatment of 3,5-( $\left.\mathrm{Ph}_{2} \mathrm{PCH}_{2}\right)_{2} \mathrm{C}_{6} \mathrm{H}_{3} \mathrm{Br}$ with 2 equiv of ${ }^{\text {t }} \mathrm{BuLi}$ at $-78{ }^{\circ} \mathrm{C}$ produces the lithium compound $\left[3,5-\left(\mathrm{Ph}_{2} \mathrm{PCH}_{2}\right)_{2} \mathrm{C}_{6} \mathrm{H}_{3^{-}}\right.$ $\mathrm{Li}]_{n}$ (3). Quenching of 3 with TMS-Cl (TMS = trimethylsilyl) yields the TMS substituted ligand $2 \mathrm{c}$ in $93 \%$ isolated yield. ${ }^{8}$ This synthesis can be envisioned as a model for the grafting of a $\mathrm{PCP}^{\prime}-\mathrm{H}$ ligand to a carbosilane dendrimer which is terminated by reactive $-\mathrm{SiR}_{2} \mathrm{Cl}$ groups. ${ }^{7 \mathrm{c}, 9}$ Our desire was then to chelate the dendrimer bound $\mathrm{PCP}^{\prime}$ ligand to a $\mathrm{Ru}$ metal center. Ruthenium(II) complexes of this class are known hydrogenation and hydrogen transfer catalysts and can participate in alkyne and aryl coupling reactions. ${ }^{3}$ To our surprise, however, treatment of $2 \mathrm{c}$ with the $\mathrm{Ru}(\mathrm{II})$ precursor $\mathrm{RuCl}_{2}\left(\mathrm{PPh}_{3}\right)_{3}{ }^{10}$ led to the isolation in $98 \%$ yield of the known para-H complex $4 \mathbf{4 a}$ (Scheme 1; i.e., incorporating the $\mathrm{PCP}^{\prime}$ fragment $2 \mathbf{b}$ ). ${ }^{3 \mathrm{a}, \mathrm{b}}$ The high yield of $\mathbf{4 a}$ indicates that aryl-Si bond cleavage (i.e., protondesilylation) is readily facilitated by the reaction conditions. ${ }^{11}$ The desilylation of ligand $\mathbf{2 c}$ could not be prevented with the addition of $\mathrm{NEt}_{3}$. Thus, the direct attachment of a $\mathrm{Ru}$ moiety on to a PCP' terminated carbosilane dendrimer cannot be accomplished in this manner because the subsequent rupturing of the aryl-Si bond will release the resulting complex from the dendrimer framework.

Fortunately, it was discovered that the reaction of the analogous complex $\mathrm{RuCl}\left[2,6-\left(\mathrm{Me}_{2} \mathrm{NCH}_{2}\right)_{2} \mathrm{C}_{6} \mathrm{H}_{3}\right]\left(\mathrm{PPh}_{3}\right)(5)^{3 \mathrm{a}, \mathrm{c}}$ reacts with ligand precursor $2 \mathrm{c}$ to give the desired complex $\mathbf{6}$ in $70 \%$ overall yield (Scheme 1). ${ }^{12}$ This reaction, which is unprecedented in the organometallic chemistry of tridentate monoanionic ligands, represents a useful synthetic protocol for

(7) Polymeric: (a) van der Kuil, L. A.; Grove, D. M.; Zwikker, J. W.; Jenneskens, L. W.; Drenth, W.; van Koten, G. Chem. Mater. 1994, 6, 16751683. (b) Pathmamanoharan, C.; Wijkens, P.; Grove, D. M.; Philipse, A. P. Langmuir 1996, 12, 4372-4377. Dendrimeric: (c) Knapen, J. W. J.; van der Made, A. W.; de Wilde, J. C.; van Leeuwen, P. W. N. M.; Wijkens, P.; Grove, D. M.; van Koten, G. Nature 1994, 372, 659-663. Also see: (d) Bhyrappa, P.; Young, J. K.; Moore, J. S.; Suslick, K. S. J. Mol. Catal. Part A: Chemical 1996, 113, 109-116.

(8) Synthesis of 2c: Prepared from a reaction of 3,5- $\left(\mathrm{Ph}_{2} \mathrm{PCH}_{2}\right)_{2} \mathrm{C}_{6} \mathrm{H}_{3}-$ $\mathrm{Br}(1.11 \mathrm{~g}, 2.0 \mathrm{mmol})$ in $\mathrm{Et}_{2} \mathrm{O}(30 \mathrm{~mL})$ with ${ }^{\mathrm{t}} \mathrm{BuLi}(2.1$ equiv, $0.6 \mathrm{M}$ pentane solution) at $-78{ }^{\circ} \mathrm{C}$, stirred $(30 \mathrm{~min})$ and then quenched with TMS-Cl (2.0 $\mathrm{mL}, 16 \mathrm{mmol})$. Yield: $1.02 \mathrm{~g}(93 \%)$, colorless oil. For full details see the Supporting Information.

(9) (a) Alonso, B.; Cuadrado, I.; Morán, M.; Losada, J. J. Chem. Soc., Chem. Commun. 1994, 2575-2576. (b) Alonso, B.; Morán, M.; Casado, C. M.; Lobete, F.; Losada, J.; Cuadrado, I. Chem. Mater. 1995, 7, 14401442. (c) Lobete, F.; Cuadrado, I.; Casado, C. M.; Alonso, B.; Morán, M.; Lasada, J. J. Organomet. Chem. 1996, 509, 109-113.

(10) (a) Hallman, P. S.; Stephenson, T. A.; Wilkinson, G. Inorg. Syn 1970, 13, 237-244. (b) Hoffman, P. R.; Caulton, K. G. J. Am. Chem Soc. 1975, 97, 4221-4228. (c) La Placa, S. J.; Ibers, J. A. Inorg. Chem. 1965, 4, 778-783.

(11) (a) von Fritz, G.; Kummer, D. Z. Anorg. Allg. Chem. 1961, 308 , 105-121. (b) Eaborn, C. Organometallic Compounds of the Group IV Elements; Vol. 1, MacDiarmid, A. G., Ed.; Marcel Dekker, Inc.: New York, 1968; Chapter 2, pp 105-536.

(12) Synthesis of 6: A solution of $2 \mathbf{c}(0.43 \mathrm{~g}, 0.78 \mathrm{mmol})$ in THF (10 $\mathrm{mL})$ was added to a boiling THF $(20 \mathrm{~mL})$ solution of $5(0.46 \mathrm{~g}, 0.79 \mathrm{mmol})$ and then refluxed for $8 \mathrm{~h}$. The final product was contaminated with a small amount $(<5 \%)$ of 1a. Yield: $0.51 \mathrm{~g}(70 \%)$. For full details see the Supporting Information. 


\section{Scheme 1}
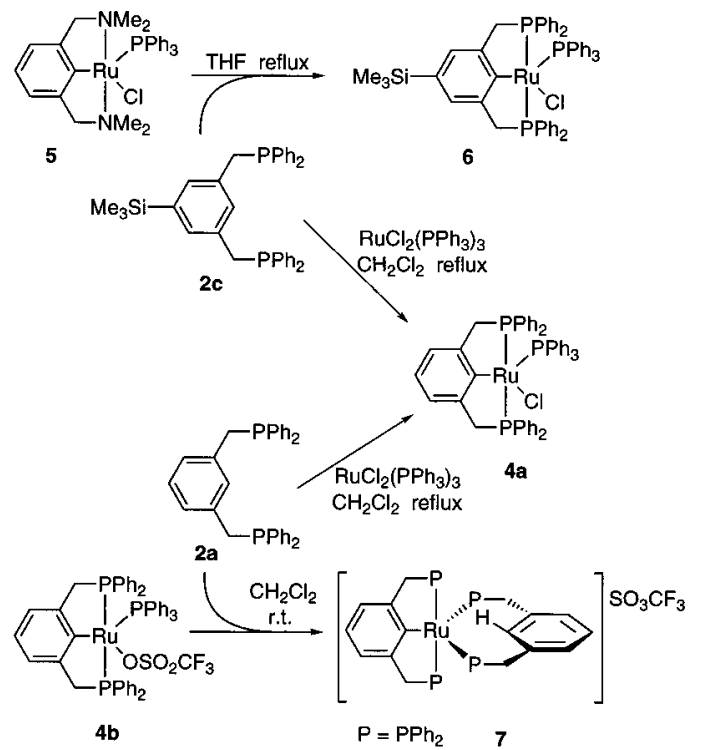

the incorporation of catalytically active $\mathrm{Ru}(\mathrm{II})$ metal centers into carbosilane dendrimers.

The cyclometalation reaction $\mathbf{2 c}$ to $\mathbf{6}$ must involve an aryl $\mathrm{C}-\mathrm{H}$ oxidative-addition/reductive-elimination (i.e., aryl $\mathrm{C}-\mathrm{H}$ bond activation) process. Attempts to monitor the conversion of 5 to $\mathbf{6}$ via NMR spectroscopy revealed the intermediacy of a $\mathrm{PCP}^{\prime}-\mathrm{H}$-bridged $\mathrm{Ru}$ dimer. ${ }^{13}$ In an attempt to gain further insight into this type of reaction, the examination of the addition of a second equiv of $\mathbf{2 a}$ with the related triflate complex $\mathbf{4 b}$ was undertaken. We chose to use the diphosphine 2a because its inherit NMR active $P$ atoms would allow for facile spectroscopic investigation. We also felt the use of the known triflate analogue of $\mathbf{4 a}$ (complex $\mathbf{4 b}$ ) was prudent as the presence of the triflate anion (kinetically, a good leaving group; although strongly bound to complex $\mathbf{4 b}, c f$. complex $\mathbf{4 a}^{3 \mathrm{a}, \mathrm{b}}$ ) may enhance the exchange of ligands from the metal coordination sphere. Treatment of $\mathbf{4 b}$ with $\mathbf{2 a}$ in $\mathrm{CH}_{2} \mathrm{Cl}_{2}$ solution led to the isolation of a yellow diamagnetic complex 7 (Scheme 1). ${ }^{14}$ The ${ }^{1} \mathrm{H}$ NMR spectrum of 7 revealed a number of aryl resonances between $\delta$ 5.9 and $7.8 \mathrm{ppm}$ in addition to a broad multiplet pattern at $\delta$ $3.4 \mathrm{ppm}$ that is assigned to the benzylic $\mathrm{CH}_{2}$ protons of the $\mathrm{PCP}^{\prime}$ fragments. The ${ }^{31} \mathrm{P}\left\{{ }^{1} \mathrm{H}\right\}$ NMR spectrum of 7 shows the presence of four magnetically distinct $\mathrm{P}$ atoms at low temperature. ${ }^{14}$ As a conclusive structural assignment of 7 could not be made from the available spectroscopic data, crystals of this compound that were suitable for X-ray structure determination were grown from a solution in $\mathrm{CH}_{2} \mathrm{Cl}_{2}$ /ether/toluene. ${ }^{15}$ The ORTEP diagram of $\mathbf{7}$ is shown in Figure 2 along with selected bond lengths and angles. The location of the hydrogen on C11 of the "incoming" trans-spanning $\mathrm{PCP}^{\prime}-\mathrm{H}$ ligand was clearly refined on the final difference map (see Supporting Information) ${ }^{15}$ and reveals that this $\mathrm{H}$ is pushed out of the plane of the arene ring forming an apparent interaction with the Ru center

(13) Full details of this bridged mechanism will be reported separately. It should be noted that the initial displacement of $\mathrm{PPh}_{3}$ by an incoming $\mathrm{PCP}^{\prime}$ ligand at room temperature is very rapid for complexes such as $\mathbf{5}$ and 6.

(14) Synthesis of 7: Ligand $2 \mathbf{a}(0.47 \mathrm{~g}, 1.0 \mathrm{mmol})$ was added to complex $4 \mathbf{b}(1.0 \mathrm{~g}, 1.0 \mathrm{mmol})$ in $\mathrm{CH}_{2} \mathrm{Cl}_{2}(15 \mathrm{~mL})$. The mixture was stirred at room temperature $(0.5 \mathrm{~h})$, and then $\mathrm{Et}_{2} \mathrm{O}$ was added to precipitate 7 as an orange solid, which was subsequently washed with $\mathrm{Et}_{2} \mathrm{O}$ and dried in vacuo. Yield: $0.97 \mathrm{~g}(81 \%)$. ${ }^{1} \mathrm{H}$ NMR $\left(200 \mathrm{MHz}, \mathrm{CD}_{2} \mathrm{Cl}_{2}, 298 \mathrm{~K}\right): \delta 3.10-3.70$ (br, $\left.4 \mathrm{H}, \mathrm{CH}_{2}\right), 6.30-7.81(\mathrm{~m}, 47 \mathrm{H}, \mathrm{ArH}) .{ }^{31} \mathrm{P}\left\{{ }^{1} \mathrm{H}\right\}$ NMR: The complicated second order spectrum is contained in the Supporting Information. The presence of large trans pseudo-coupling constants and smaller cis coupling constants strongly suggest that the solid-state structure of $\mathbf{7}$ is retained in solution. Examination of complex 7 via $2 \mathrm{D}^{31} \mathrm{P}-{ }^{31} \mathrm{P}$ NMR (large couplings are fully resolved) spectroscopy also supports this conclusion. Full details of the NMR characterization of 7 will be reported in a forthcoming full paper. Anal. Calcd (Found) for $\mathrm{C}_{65} \mathrm{H}_{55} \mathrm{O}_{3} \mathrm{~F}_{3} \mathrm{P}_{4} \mathrm{SRu} \cdot 0.75 \mathrm{CH}_{2} \mathrm{Cl}_{2}$ : C 62.61 (62.93), H 4.48 (4.56).

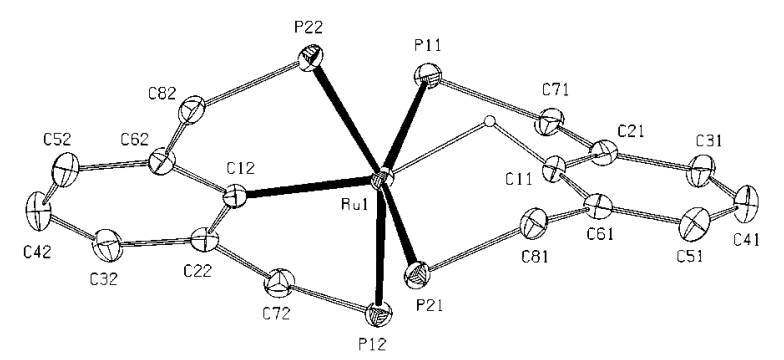

Figure 2. Perspective view (ORTEP, 50\% probability) of cation 7, showing aryl $\mathrm{C}-\mathrm{H} \cdots \mathrm{Ru}$ interaction. Other protons and phenyl groups have been omitted for clarity. Bond distances $(\AA)$ and angles (deg): Ru1-P11 2.3732(9), Ru1-P21 2.4432(9), Ru1-P12 2.3716(9), Ru1-

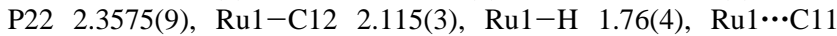
2.395(4), C11-H 1.15(4), P11-Ru1-P21 152.74(3), P12-Ru1-P22 153.64(3), P11-Ru1-P12 91.62(3), P11-Ru1-P22 95.89(3), C11-Ru1-C12 171.47(11), Ru1-H-C11 109(3).

of a cationic $\left[\mathrm{PCP}^{\prime} \mathrm{Ru}\right]^{+}$fragment (i.e., either an agostic type $\mathrm{C}-\mathrm{H} \cdots \mathrm{M}$ interaction or a $3 \mathrm{c}-2 \mathrm{e}$ bond are limiting interaction models). ${ }^{3 n, 16}$ The local symmetry around the metal center is best described as a highly distorted octahedral environment. The inequivalence of all four $\mathrm{P}$ donor atoms is clearly visible in the structure, and the ${ }^{31} \mathrm{P}\left\{{ }^{1} \mathrm{H}\right\} \mathrm{NMR}$ data strongly suggest that this geometry is retained in solution. This complex also confirms our recent proposal that chelation of the neutral $\mathrm{PCP}^{\prime}-\mathrm{H}$ ligand occurs via initial trans coordination of both $\mathrm{P}$ atoms and that this precedes electrophilic attack of the metal center on the $\mathrm{C}-\mathrm{H}$ bond. ${ }^{3 \mathrm{a}}$ Our attempts to observe the appropriate ${ }^{1} \mathrm{H}$ and ${ }^{13} \mathrm{C}$ nuclei of the $\mathrm{C}-\mathrm{H} \cdots \mathrm{Ru}$ interaction have thus far been thwarted by the large number of aromatic resonances and low abundance of the signals of interest. An IR study of 7 did reveal, however, a medium intensity band at $2864 \mathrm{~cm}^{-1}$, which is tentatively assigned to the agostic $\mathrm{C}-\mathrm{H}$ stretching vibration. ${ }^{16}$ Deuteration and ${ }^{1} \mathrm{H},{ }^{31} \mathrm{P}$ heteronuclear decoupling $\mathrm{NMR}$ experiments are currently underway to unequivocally assign the agostic $\mathrm{C}-\mathrm{H}$ fragment.

In conclusion, this report has shown that the incorporation of reactive $\mathrm{Ru}(\mathrm{II}) \mathrm{PCP}^{\prime}$ complexes into carbosilane dendrimers can be accomplished by a facile ligand displacement of the $\mathrm{NCN}^{\prime}-\mathrm{H}$ ligand (1a) from compound 5. Attempts to directly add the $\mathrm{Ru}$ metal center via the traditional precursor $\mathrm{RuCl}_{2}$ $\left(\mathrm{PPh}_{3}\right)_{3}$ leads to aryl-Si bond cleavage and hence would result in degradation of the dendrimer molecule. The direct observation of an intermediate in the $\mathrm{C}-\mathrm{H}$ bond activation of a neutral $\mathrm{PCP}^{\prime}-\mathrm{H}$ ligand has been shown for the first time in these systems and has confirmed that most likely $\mathrm{P}$ donor chelation precedes $\mathrm{C}-\mathrm{H}$ bond activation with a $\mathrm{d}^{6} \mathrm{Ru}(\mathrm{II})$ metal center. We are currently pursuing an extended investigation of this novel $\mathrm{C}-\mathrm{H}$ bond activation chemistry in addition to the attachment of complexes similar to $\mathbf{6}$ to dendrimeric macromolecules.

Acknowledgment. We thank the Conselho Nacional de Desenvolvimento Científico e Tecnológico (CNPq, Brazil), the Swiss National Science Foundation, CIBA-GEIGY-Jubiläums-Stiftung, the Netherlands Foundation of Chemical Research (SON), and the Netherlands Organization for Scientific Research (NWO) for financial support.

Supporting Information Available: Tables of crystal data, thermal parameters, bond distances, bond angles, and atomic coordinates for 7 and the ${ }^{31} \mathrm{P}\left\{{ }^{1} \mathrm{H}\right\}$ NMR spectra of 7 (210 and $\left.298 \mathrm{~K}\right)$ and the detailed syntheses and NMR data for $2 \mathrm{c}$ and 6 (24 pages). See any current masthead page for ordering and Internet access instructions.

\section{JA9710060}

(15) Crystal data for 7: $\left[\mathrm{C}_{64} \mathrm{H}_{55} \mathrm{P}_{4} \mathrm{Ru}\right]\left[\mathrm{CF}_{3} \mathrm{O}_{3} \mathrm{~S}\right] \cdot \mathrm{CH}_{2} \mathrm{Cl}_{2} \cdot \mathrm{C}_{4} \mathrm{H}_{10} \mathrm{O}, M_{\mathrm{r}}=$ 1357.23, triclinic, space group $P 1, a=12.7745(11), b=15.8943(11), c=$ $17.0745(11) \AA, \alpha=110.669(5), \beta=96.973(6), \gamma=101.871(6)^{\circ}, V=$ $3102.2(4) \AA^{3}, D_{\mathrm{x}}=1.453 \mathrm{~g} \mathrm{~cm}^{-3}, Z=2, T=150 \mathrm{~K}, \mathrm{MoK} \alpha, R_{1}=0.0461$ for 10014 reflections with $I>2 \sigma(I)$. The hydrido $\mathrm{H}$ was located from a difference map and its position refined

(16) (a) Brookhart, M.; Green, M. L. H.; Wong, L.-L. Prog. Inorg. Chem 1988, 36, 1-124. (b) Crabtree, R.; Hamilton, D. G. Adv. Organomet. Chem. 1988, 28, 299-338. 